Southern Hemisphere, especially if the war occurred in July rather than January. In particular, interactive climatic modelling suggests a lowering of tropopause (the boundary between the troposphere and the overlying stratosphere) from its present heights of roughly $9 \mathrm{~km}$ in high latitudes and $20 \mathrm{~km}$ over the tropics to about $4 \mathrm{~km}$ over the North Pole and $10 \mathrm{~km}$ in the Southern Hemisphere. This, in turn, would mean that a considerable amount of smoke, perhaps 60 million tonnes, enters the stratosphere where it has two climatic effects. First with an optical thickness of 0.1 to 0.5 , the smoke results in concomitant reduction in global insolation of roughly 20 per cent. Second, a July war would cause some smoke to drift into the Southern Hemisphere, with the general consequence of reduced global precipitation. In particular, cooling over the Tibet plateau turns off the southwest monsoon. But it has to be emphasized that there remain significant uncertainties in such calculations because the models do not take account of the potential effects of precipitation.

Although much more research is needed into the implications of these climatic changes for both natural ecosystems and agriculture, the results give cause for concern. The areas likely to suffer the worst effects of nuclear winter, the tundra and boreal forests, are the best equipped to cope, noted T.C. Hutchinson of the University of Toronto, because they are naturally adapted to extremes of climate. But the tropical mangrove and evergreen rain forests have no such protection and are very vulnerable to damage by sub-zero temperatures lasting only a few days or weeks.

The effects on agriculture could be even worse, said M.A. Harwell (of Cornell University). What emerges is that although a July war would have more severe immediate and short-term climatic effects than one fought in January, the precise timing may be important. For example the occurrence of just one or two nights with temperatures below $15^{\circ} \mathrm{C}$ at a critical period in the growing season could wipe out an entire rice harvest. And perhaps as little as a $3^{\circ} \mathrm{C}$ fall in temperature would be sufficient almost to eliminate Canadian wheat producion. This loss of production, combined with the likely absence of imports, would be disastrous for most of the surviving world population. For example, on loss of imports alone, even assuming 100 per cent of present production, Japan could only feed half of its present population. And most underdeveloped countries appear to have only about four months supply of stored food. If the climatic effects of a nuclear winter in July lie towards the colder end of the range physicists consider plausible, the ensuing lack of food may have a greater impact on the global population than the immediate effects of the nuclear attacks.

Peter Gambles
Sakharov

\section{Mystery on the cards}

Relatives of Academician Andrei Sakharov living in the United States are becoming increasingly concerned about his whereabouts and well-being. They know of nobody who has seen either Sakharov or his wife, Elena Bonner, in their Gor'kii exile, since February. During April, they received reports that Sakharov had begun another protest fast, and that he was conveyed to hospital for forced feeding on 21 April. A postcard signed by the couple (see illustration) also apparently dated 21 April, which represents them as commencing their spring-cleaning on that date, now proves to have been tampered with in transmission to conceal an original date of 1 April.

During the past two months, there have been many conflicting reports about the Sakharovs, including rumours that they were to be released to the West under an amnesty to mark the 40th anniversary of the end of the Second World War in Europe, and even that they had already arrived in Zurich. (These rumours may have emanated from Soviet official sources, in order to defuse international tensions before the Ottawa Human Rights "Helsinki Review" meeting.) Sakharov was also said to be threatening to resign

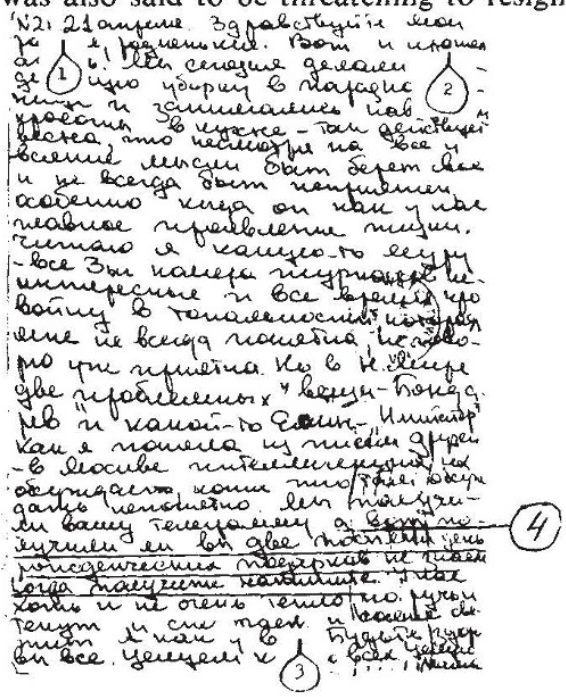

The 1 April or 21 April card.

from the Academy of Sciences in protest at the passivity of his fellow academicians regarding his plight and that of his wife, who has been refused permission to travel to the West for eye surgery. The arrival on 25 May of the " 21 April" postcard initially led the relatives in Boston to have "serious doubts" about the protest fast, and to be more optimistic.

Closer examination, however, revealed a number of anomalies. Because mail from the Soviet Union frequently fails to arrive, Mrs Bonner numbers all postcards (the couple are apparently not allowed to write letters). The card dated " 21 April" was numbered 21 , but the family had previously received cards numbered 22 (dated 3 April) and 26 (dated 17 April). The latter took two weeks to arrive, while card number 21 apparently took 34 days. Moreover, on card no. $21 \mathrm{Mrs}$ Bonner asked if the family had received the birthday presents that she had sent [marked " 4 "' in illustration] while card 22 (3 April) says: "the day before yesterday we received a card from mother saying that the birthday presents for Sasha and Tanya have arrived".

Furthermore, card 21 contains an odd sentence (with a grammatical error in the verb-form) which seems to imply that the snow had melted (past tense) [3] and the gutters were now running with water (present tense). In card 22 (3 April), Mrs Bonner had reported the snow almost all gone, and according to the Pravda weather reports there was no snow in the Gor'kil area during the last ten days of April.

The relatives therefore took the postcard, and the thirteen other cards received from the Sakharovs this year, to Charles Gershin, a certified master graphoanalyst in Massachusetts. Gershin knows no Russian, but the Russian cursive script, unlike printed Cyrillic, is based on the Latin alphabet. Examination under high-power magnification, therefore, made it possible for Gershin to detect interference. $\mathrm{He}$ found that on card 21 :

- A " 2 " had been inserted before the date [1] which had originally read 1 April.

- The alteration of a single letter in line 2 had changed an original "April has gone" [2] (somewhat premature if written on the 21 st) to "April has come".

- Similarly the alteration of one letter in the sentence about the snow changes an original "is melting" to "has melted" (with an unavoidable grammatical error).

The implication, therefore, is that the card number was tampered with in order to give the impression that the Sakharovs were leading their "normal" lives on 21 April, from which the logical conclusion would be that something untoward must have occurred. The unconfirmed reports of Sakharov's alleged fast state that he began it on 16 April, so how would the "tamperers" have had to hand the card mailed on 1 April? One possibility is that for some reason, the censors had decided to withhold this card anyway, and then, when the story of forced-feeding broke on 15 May, the security authorities quickly looked through their stock of recent cards for anything that could be doctored.

The relatives in Boston are now unwilling to commit themselves on any report about Sakharovs, even whether they are alive or dead. According to Dr Efrem Yankelevich, Mrs Bonner's son-in-law, several friends in Moscow apparently received messages from the Sakharovs on 20 May (the eve of Dr Sakharov's birthday), but these were sent by facsimile, which, he says bitterly, "are even easier to forge than a postcard".

Vera Rich 